\title{
Chemical Spray Pyrolysis pure and Transition Metal doped Structural, Morphological and Optical properties of SnS Thin Films
}

\author{
S. Selvi ${ }^{1}$, M.Karunakaran ${ }^{2} *$ K. Kasirajan ${ }^{3}$ \\ ${ }^{1,2,3}$ Department of Physics, Alagappa Government Arts College, Karaikudi, India- 630003 \\ "Corresponding Author: tvdkaruna@gmail.com, Tel.: +91-8122841591
}

Available online at: www.isroset.org

Received: 03/Apr/2019, Accepted: 26/Apr/2019, Online: 30/Jun/2019

\begin{abstract}
Cadmium doped tin sulfide (SnS) is a promising low cost photovoltaic material for its direct optical band gap $(\sim 1.4$ $\mathrm{eV})$. In this report cadmium doped tin sulfide thin films were prepared by chemical spray Pyrolysis method. The precursor solution cadmium chloride, tin chloride and thiourea are dissolved in de-ionized water. All the deposited films are characterized by different technique such as structural, morphological and optical properties have been studied. The XRD pattern the films are polycrystalline in nature and orthorhombic structure. The average particle size decreased with increasing transition metal doping concentration. SEM image reveals the cornflake shape. The FTIR spectrum used to confirm the functional group of $569 \mathrm{~cm}^{-1} \mathrm{Sn}-\mathrm{S}$ bond. The optical transmission spectra of transition metal doped SnS thin films the average transmission $60 \%$ in the visible region, the doping level increase the optical band gap values also increased from 1.4- 1.7 eV. PL spectra of all samples exhibited a broad emission in the visible range.
\end{abstract}

Keywords - Sulfide, Transition Metal, XRD, Cornflake shape, Band gap.

\section{INTRODUCTION}

In recent years the metal sulfides have been attracted in the field of photovoltaic and super capacitor applications. The thin films are widely used in fabrication of photovoltaic devices. Tin Sulfide ( $\mathrm{SnS}$ ) belongs to group IV-VI semiconductor with orthorhombic crystal structure. It's low cost, abundant and non toxic material [1]. During the last decades thin film solar cells have attracted. Materials containing post-transition metals with an $\mathrm{ns}^{2}$ electronic configuration (e.g. $\mathrm{Pb}^{2+}, \mathrm{Sn}^{2+}, \mathrm{Ge}^{2+}, \mathrm{Sb}^{3+}$ and $\mathrm{Bi}^{3+}$ ) are attracting significant recent attention for their ability as solar absorbers [2]. Recently tin sulfide ( $\mathrm{SnS}$ ) thin films have emerged as alternative absorber layers and promising material for low coast thin films solar cells technology. The direct band gap is 1.3 and $1.5 \mathrm{eV}$ [3]. Tin sulfide is a binary semiconductor with wide range of applications and optoelectronic devices [4]. In recent years, tin chalcogenide compounds such as $\mathrm{SnS}^{2}, \mathrm{SnS}_{2}$ have role in fabrication of photovoltaic devices. Tin mono sulfide ( $\mathrm{SnS}$ ) is very promising material for the optoelectronic devices and direct band gap around $1.35 \mathrm{eV}$ [5]. In tin sulfide thin films, loferski theoretically proved that a maximum efficiency of $25 \%$ is achievable for this material [6]. Due to optimum band gap, high absorption coefficient and p-type conductivity, $\mathrm{SnS}$ results to be a suitable candidate for absorber layer in thin film solar cells whereas $\mathrm{SnS} 2$ for window layer because of the wider band gap and n-type conductivity [7]. The $\mathrm{SnS}$ thin films can be prepared by several methods such as Spray Pyrolysis technique [8-11], Successive Ionic Layer Absorption and Reaction Method (SILAR) [12], Magnetron Sputtering [13], Chemical Bath Deposition [14], Pulsed Laser Irradiation [15], Spin Coating [16].

Among these methods Spray Pyrolysis technique is simple, low cost, and large area coatings. The coated films are well crystalline and homogeneous deposits with thickness. Some metal elements such as $\mathrm{Bi}, \mathrm{Sb}, \mathrm{Ag}, \mathrm{Cu}, \mathrm{Cd}$, and In were doped into SnS films to improve the properties [17]. There are very few result are available in the Cd doped $\mathrm{SnO}_{2}$ thin films by different deposition techniques for the optoelectronics and transparent electrodes [18-19]. But no result in the Cd doped SnS thin films by chemical Spray Pyrolysis technique, so we tried to investigate the cadmium doped SnS thin films by the spray Pyrolysis technique.

In this present work, we have introduced an excellent Spray Pyrolysis technique. The SnS thin films have been deposited on micro class substrates. The structural, surface morphological and optical properties of the films have been investigated as a function of the films.

\section{MATERIALS AND METHODS}


Tin Chloride $\left(\mathrm{Sncl}_{2} \cdot 5 \mathrm{H}_{2} \mathrm{O}\right)$, Thiourea ((NH2)2CS) and Cadmium Chloride $\left(\mathrm{CdCl}_{2} .5 \mathrm{H}_{2} \mathrm{O}\right)$ is purchased from Merck, India and de-ionized water was used throughout the reaction process.

\section{Preparation of Transition metal doped Tin Sulfide Thin Films}

Pure and transition metal doped Tin sulfide $(\mathrm{SnS})$ thin films have been deposited on the micro class substrate with different doping level of cadmium using chemical Spray Pyrolysis technique. The precursor solution is prepared using $\mathrm{Sncl}_{2} \cdot 5 \mathrm{H}_{2} \mathrm{O}$ and thiourea $\left(\left(\mathrm{NH}_{2}\right)_{2} \mathrm{CS}\right)$ both solutions were mixed and diluted with $40 \mathrm{ml}$ de-ionized water with constant stirring for one hour. Well cleaned glass substrate of dimension $75 \times 25 \mathrm{~mm}^{2}$ dimensions at the substrate distance $30 \mathrm{~cm}$. Cadmium was doped with Tin Sulfide $(\mathrm{SnS})$ thin films using $\mathrm{CdCl}_{2}$ (5 at \%, 10 at\%) as the doping source. The prepared solution was sprayed onto ultrasonically cleaned glass substrates kept at $250^{\circ} \mathrm{C}$. Films prepared by this method have uniform thickness and well adherent with the substrate. The Optimum thermal/ spray Pyrolysis deposition condition for the preparation of $\mathrm{Cd}$ doped $\mathrm{SnS}$ thin films are listed in Table 1.

Table.1: Optimum thermal / spray Pyrolysis deposition conditions for the preparation of pure and transition metal doped SnS Thin Films

\begin{tabular}{|l|l|}
\hline Precursor molar concentration & $0.1 \mathrm{M}$ \\
\hline Cadmium concentration & $0 \%, 5 \%$ and $10 \%$ \\
\hline Solvent volume & $40 \mathrm{ml}$ \\
\hline Substrate temperature & $250^{\circ} \mathrm{C}$ \\
\hline Substrate to nozzle distance & $25 \mathrm{~cm}$ \\
\hline Spray angle & $45^{\circ}$ \\
\hline Spray interval & $10 \mathrm{~min}$ \\
\hline
\end{tabular}

$\mathrm{X}$-ray diffraction (XRD) analysis was performed on X-ray diffractometer (PAN analytical X-Pert PRO) operated at 40 $\mathrm{kV}$ and $30 \mathrm{~mA}$. The pattern was recorded by $\mathrm{Cu}-\mathrm{K} \alpha$ radiation with of $1.54056 \AA$. Scanning rate of $2 \% \mathrm{~min}$ and a sample interval of $0.02^{\circ}$ were employed in the $2 \theta$ range from $10^{\circ}$ to $80^{\circ}$ for the determination of crystallinity, purity and crystallite size of the Thin Films. The average grain size of the $\mathrm{Cd}$ doped $\mathrm{SnS}$ Thin Films calculated using Scherrer formula $\mathrm{D}=0.89 \lambda / \beta \operatorname{Cos} \theta$. Where, $\mathrm{d}$ is diffraction angle, constant value of $(\mathrm{k})=0.89, \lambda$ - wavelength and $\beta$ is the FWHM (full width half maximum) of consistent peak, $\theta=$ Bragg's reflection angle. Size and surface morphology of $\mathrm{Cd}$ doped SnS Thin Films was examined by JEOL JSM 6390 Scanning Electron Microscope (SEM) instrument operated at an accelerating voltage at $15 \mathrm{Kv}$. Elemental analysis was carried out by Energy Dispersive (X-ray) EDAX analysis, the particles were dried on a carbon coated copper grid and performed on SEM instrument with thermos EDAX attachment. The FTIR analysis of the thin films was performed by Perkin Elmer make Model Spectrum RX1
(Range $4000 \mathrm{~cm}^{-1}-400 \mathrm{~cm}^{-1}$ ) using $\mathrm{KBr}$ compressed pellet method. The optical studies were carried out by Perkin Elmer Lambda 35 UV-VIS-NIR double beam spectrophotometer for a wavelength range of $300 \mathrm{~nm}$ to $1100 \mathrm{~nm}$. Photoluminescence was observed from the Varian carry eclipse PL spectrograph.

\section{RESUlTS AND DISCUSSION}

\section{Structural Analysis}

Figure.1 shows the X-ray diffraction pattern of pure and transition metal doped SnS Thin Films with different doping concentrations. The diffraction peaks are observed at the deposited films like $2 \theta$ value of $32.5^{\circ}, 35.5^{\circ}, 38.9^{\circ}, 46.2^{\circ}$, $48.8^{\circ}, 61.5^{\circ}, 66.5^{\circ}$ and $68.8^{\circ}$ are corresponding to the crystal planes of (021), (011), (111), (311), (411), (201), (301) and (240) respectively. The preferential orientation along the sharp peaks at (111) planes good agreement with the standard JCPDS card no- (75-2115) with the standard orthorhombic crystal structure. It indicates the maximum number of crystallites have appear in the (111) plane direction. In addition to that small shift is observed for the peaks $(021),(011)$ and (311) for all the deposited films. The observed marginal shift is attributed to presence of strain between a substrate and the deposited films [5]. The doping molar concentration of the films produces a considerable decrease in crystalline, because of the dopant concentration should be increased. The average crystalline size of the transition metal doped $\mathrm{SnS}$ coated films is around 27 to 55 $\mathrm{nm}$. The structural parameters such as average crystalline size (D), dislocation density $(\varepsilon)$, micro strain $(\delta)$, and Lattice Distortion (LD) of the films are calculated using the relations [20].

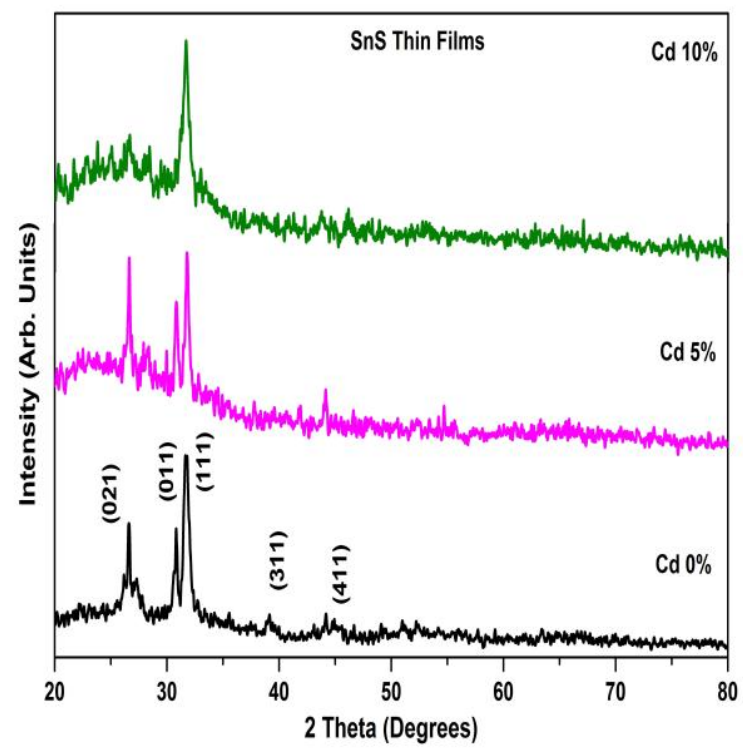

Fig. 1 XRD patterns of pure and transition metal doped $\mathrm{SnS}$ thin films with different doping concentrations. 
The average crystalline size was estimated by DebyeScherer's relation as

$$
\mathrm{D}=\frac{k \lambda}{\beta \operatorname{Cos} \theta}
$$

Where the constant ' $k$ ' is the shape factor $=0.94$, ' $\lambda$ ' is wavelength of X-rays (1.5406 $\AA^{\left.-\mathrm{CuK}_{\alpha}\right)}$ ' $\theta$ ' is the Bragg's angle and ' $\beta$ ' is FWHM. The value of dislocation density was calculated using the relation

$$
\delta=\frac{1}{D^{2}}
$$

The lattice strain $(\varepsilon)$ was calculated using the relation

$$
\varepsilon=\frac{\beta \operatorname{Cos} \theta}{4}
$$

The lattice distortion (LD) is calculated using the relation such as [21]

$$
\mathrm{L} . \mathrm{D}=\frac{\beta}{4 \tan \theta}
$$

The micro structural parameters of pure and transition metal doped tin sulfide films is listed in table 2.

\begin{tabular}{|c|c|c|c|c|}
\multicolumn{2}{c|}{ Table - 2: Micro - structural parameters } \\
$\begin{array}{c}\text { Cd Doping } \\
\text { Level }\end{array}$ & $\begin{array}{c}\text { Crystallite } \\
\text { Size } \\
(\mathrm{D}) \times 10^{-9} \mathrm{~m}\end{array}$ & $\begin{array}{c}\text { Dislocation } \\
\text { density } \\
\delta \times\left(10^{16}\right. \\
\text { lines/m) }\end{array}$ & $\begin{array}{c}\text { Micro Strain } \\
\varepsilon \times\left(10^{-3}\right. \\
\left.\text { Lines }^{-2} \mathrm{~m}^{-4}\right)\end{array}$ & $\begin{array}{c}\text { Lattice } \\
\text { Distortion } \\
(\mathrm{LD}) \\
\times\left(10^{-3}\right)\end{array}$ \\
\hline $0 \%$ & 55.87 & 0.3203 & 0.9972 & 2.2792 \\
\hline $5 \%$ & 33.58 & 0.88661 & 1.67140 & 3.7667 \\
\hline $10 \%$ & 27.977 & 0.78271 & 2.0156 & 4.536 \\
\hline
\end{tabular}

The doping concentration increases $(5 \%, 10 \%)$, then crystalline size also decreased. Otherwise the micro strain, dislocation density, lattice distortion and stacking fault probability increased.

\section{Morphological and Compositional Analysis:}

Fig. 2(a)-(b) shows the SEM micrographs of pure and transition metal doped tin sulfide thin films with the different doping concentrations. The SEM images around $200 \mathrm{~nm}$ magnifications. The surface morphology is remarkable consequence on the performance of the thin films. All the deposited films are homogeneous and polycrystalline in nature. The transition metal doped tin sulfide thin films are formed by cornflake like particles, homogeneous, with uniform surface and good adhesion to substrates. Substrates are well covered and no pinholes are observed [22]. The average particle size is around $20 \pm 5 \mathrm{~nm}$.

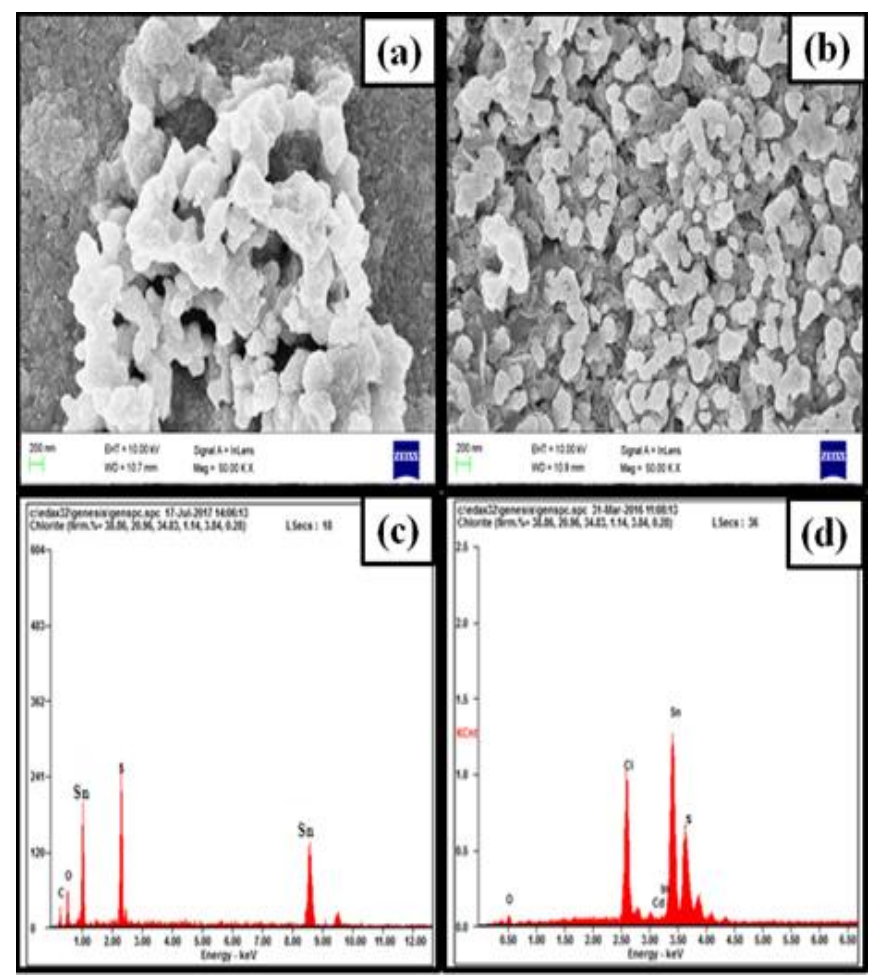

Fig. 2: (a)-(b) \& (c)-(d) SEM and EDAX Spectrum of pure and 2\% Cd doped SnS thin films.

In Fig. 2(c)-(d) we have announced a historic EDX spectrum of pure and transition metal doped $\mathrm{SnS}$ thin films. As we can see, $\mathrm{Sn}, \mathrm{S}$ and $\mathrm{Cd}$ elements are presents in the film composition along with $\mathrm{C}, \mathrm{O}$ and $\mathrm{Cl}$. $\mathrm{O}$ and $\mathrm{C}$ may originate from methanol and thiourea [3].

\section{FTIR Analysis:}

In the FTIR studies is used to find the molecules and functional groups presence in the deposited thin films. The FTIR spectrum of pure and transition metal doped $\mathrm{SnS}$ thin films are shown in figure 3. The FTIR spectrum of observed that the peaks located at (3271) (2954) (926) (615) (569) (458) $\mathrm{cm}^{-1}$ respectively. A small absorption peak is observed at 569 and $686 \mathrm{~cm}^{-1}$ are possibly due to the stretching vibrations of Sn-S [12]. A broad band appears at 3250-3500 $\mathrm{cm}^{-1}$, which is due to $\mathrm{OH}$ stretching vibration. Strong and sharp bands appear in the spectrum at 615, 1000-1200 and $2354 \mathrm{~cm}^{-1}$, which are due to the characteristics peaks of $\mathrm{SnS}$ [23]. 


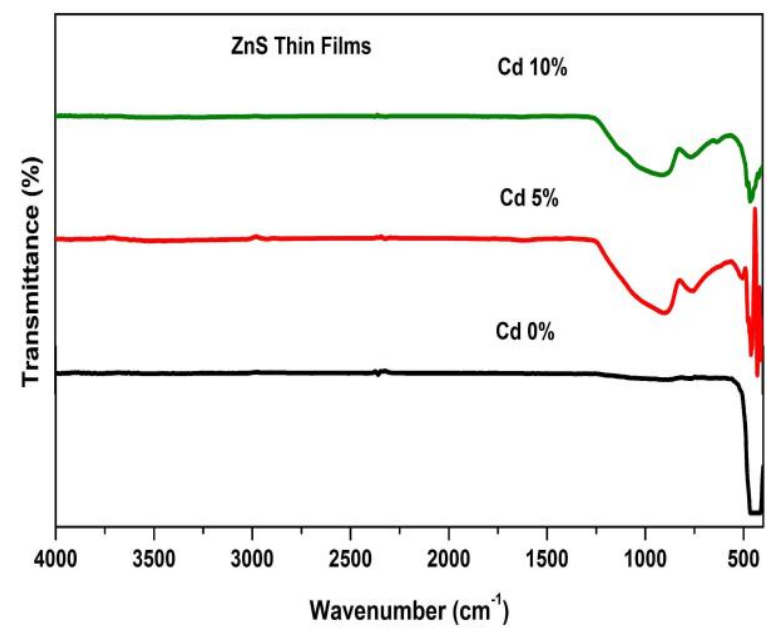

Fig. 3: FTIR spectrum of pure and transition metal doped SnS thin films.

\section{Optical properties}

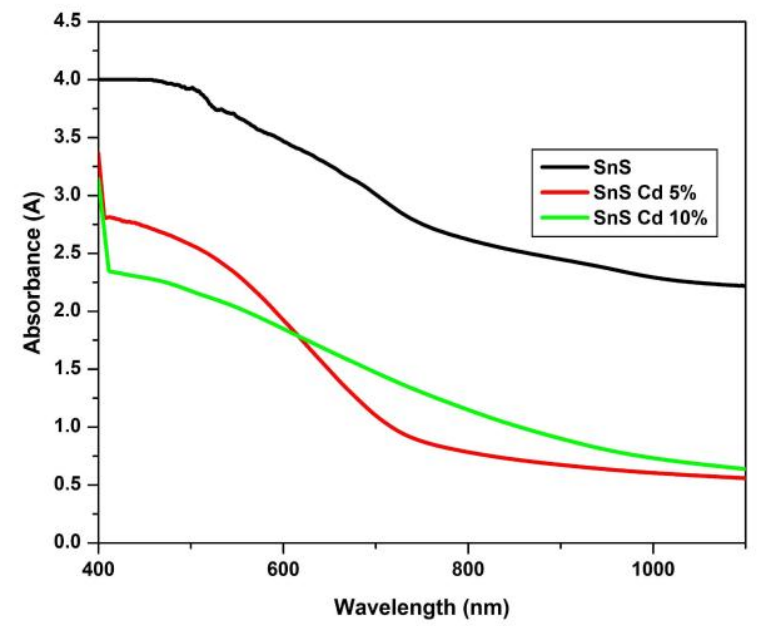

Fig. 5: UV-Vis absorption spectra

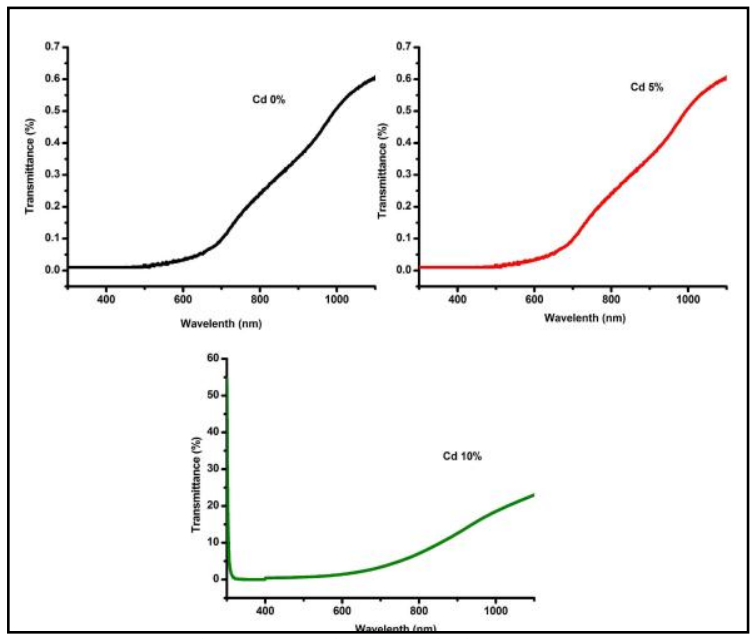

Fig. 5: UV-Vis transmission spectra.

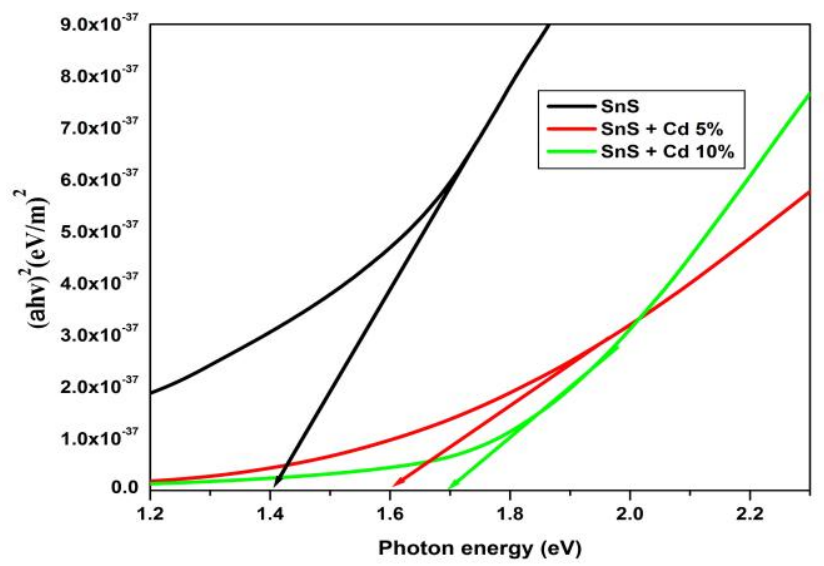

Fig. 6: UV-Vis Tauc plate

The optical transmission spectra of pure and transition metal doped SnS deposited thin films at different doping percentage of wavelength range from $200-1200 \mathrm{~nm}$. The average transmission $60 \%$ in the visible region, but the doping level increase the optical transmittance value increased is show in figure 4. The doping level increase the maximum transparency of the deposited film is acquired. The absorption spectra of pure and transition metal doped $\mathrm{SnS}$ thin films deposited on the micro class substrate with different doping percentages were studied in the wavelength range 500-1200 $\mathrm{nm}$. The optical band gap values for these films were evaluated using the Tauc plots (Fig. 5.) The nature of the transition involved (direct or indirect) during the absorption process was determined by studying the dependence of the absorption coefficient $\mathrm{A}$, on photon energy $h \gamma$ as calculated using the relation as [24].

$$
\alpha h v=A\left(h v-E_{g}\right)^{n}
$$

Where $\mathrm{A}$ is the constant, $\mathrm{E}_{\mathrm{g}}$ is the band gap energy, hy is the photon energy, the plots of (ahy) ${ }^{2}$ versus hy for different substrate temperatures are shown in the Fig. 6. The direct band gap energy of pure $1.3 \mathrm{eV}$ which is in good agreement with the value reported in the literature [25]. It was seen that the direct band gap values increased from $1.4-1.7 \mathrm{eV}$ with increased in doping molar concentrations. Optical band gap values of pure and Transition metal doped Tin Sulfide thin films are shown in Table - 3. This is a way of achieving band gap tuning in semiconductor materials and hence the development of new thin films for efficient photovoltaic application. As that doping percentage increased, the sharp absorption edge was formed because the grain size increased has they became more crystalline [26].

Table - 3. Optical band gap values

\begin{tabular}{|c|c|}
\hline Film & $\begin{array}{c}\text { Direct Energy } \\
\text { Band Gap (eV) }\end{array}$ \\
\hline Pure SnS & 1.4 \\
\hline $5 \%$ Cd Doped SnS & 1.6 \\
\hline $10 \%$ Cd Doped SnS & 1.7 \\
\hline
\end{tabular}




\section{Photoluminescence Analysis:}

Fig 7 shows the photoluminescence spectra of pure and transition metal doped $\mathrm{SnS}$ thin films with different $\mathrm{Cd}$ percentage $(5 \%, 10 \%)$ variations. The broad peak entered between $470-540 \mathrm{~nm}$ at an excitation wavelength is 550 $\mathrm{nm}$. The yellow and red bands are associated with the point defects and surface states, respectively. On the other hand, the origins of green and orange bands are due to the atoms or excitonic transitions and the $\mathrm{I}_{\mathrm{Cd}}-\mathrm{V}_{\mathrm{Cd}}$ complex defects, respectively [27].

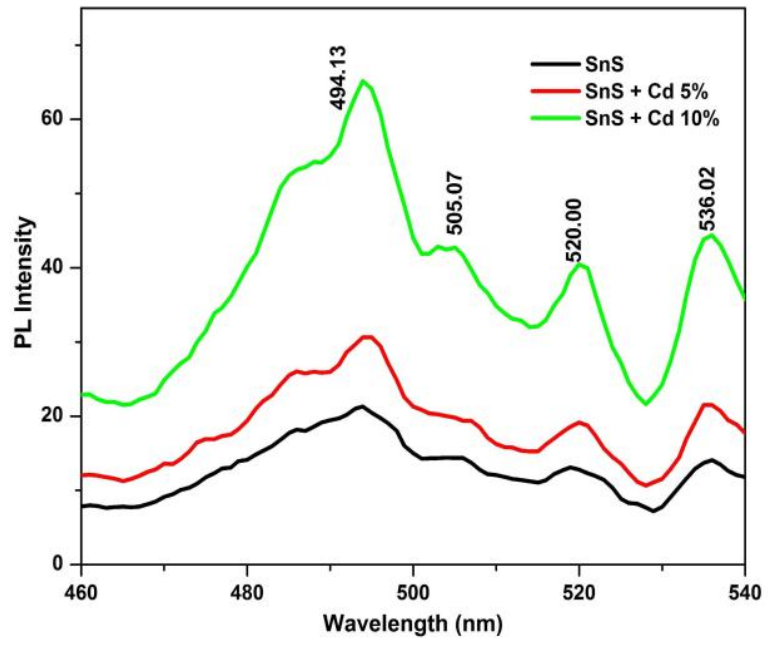

Fig. 7: photoluminescence spectra

In the XRD measurement in which the intensity of (111) planes predominant peak has increase in the 10 at. $\%$. The strong band-edge emission around $495 \mathrm{~nm}$ the emission peak improved because of doping $\mathrm{Cd}$ level. Ac-cording to quantum confinement theory, the energy band gap of a semiconductor depends on the crystal size; its value will increase with a decrease in crystal size from our XRD pattern [28]. In the possible reason transition metal doped Tin Sulfide deposited films the doping molar concentrations increases up to 10 at.\% the band-edge emission peak shifted the higher wavelength region.

\section{CONCLUSION}

Effect of transition metal doped on structural, morphological and optical properties of Tin Sulfide thin films deposited by chemical spray Pyrolysis technique have been investigated. The XRD pattern shows that all the deposited films have polycrystalline in nature the preferential orientation along the sharp peaks at (111) plane as the preferred orientation orthorhombic crystal structure. The Cadmium doping the crystalline size also decreased from 55- $27 \mathrm{~nm}$. SEM study reveals that the films are uniform, dense and cornflake shape. FTIR shows the strong and weak bands associated with deposited films. The transmittance value in the visible region was found to be $60 \%$ and optical band gap value is increased from $1.4-1.7 \mathrm{eV}$. In the PL spectra the broad peak entered between $470-540 \mathrm{~nm}$ at an excitation wavelength is 550 nm.

\section{REFERENCES}

[1] Samani, Narjes Kabiri, Zahra Dehghani Tafti, Hojjat Amrollahi Bioki, Mahmood Borhani Zarandi, and Shirin Shayegh. "Annealing effect on structural and optical constants of SnS thin films for solar cells application." Optik, Vol. 131, pp 231-241, 2017.

[2] Catherall, Amanda L., Shasa Harris, Michael S. Hill, Andrew L. Johnson, and Mary F. Mahon. "Deposition of SnS Thin Films from Sn (II) Thioamidate Precursors. " Crystal Growth \& Design, Vol. 17, Issue. 10, pp 5544-5551, 2017.

[3] Messaoudi, M., M. S. Aida, N. Attaf, T. Bezzi, Jamal Bougdira, and G. Medjahdi. "Deposition of tin (II) sulfide thin films by ultrasonic spray pyrolysis: Evidence of sulfur exodiffusion." Materials Science in Semiconductor Processing, Vol. 17, pp 38-42, 2014. Jiang, Feng, Honglie Shen, and Jin Jiao. "Formation of photoconductive SnS thin films through reaction of Sn-metal films in sulfur-vapor." ECS Journal of Solid State Science and Technology, Vol. 2, Issue. 11, pp 478-484, 2013.

[4] Reddy, T. Srinivasa, and MC Santhosh Kumar. "Co-evaporated SnS thin films for visible light photodetector applications." RSC Advances, Vol. 6, Issue. 89, pp 95680-95692, 2016.

[5] Sajeesh, T. H., Anita R. Warrier, C. Sudha Kartha, and K. P. Vijayakumar. "Optimization of parameters of chemical spray pyrolysis technique to get $n$ and p-type layers of SnS." Thin Solid Films, Vol. 518, Issue. 15, pp 4370-4374, 2010.

[6] Andrade-Arvizu, Jacob A., Maykel Courel-Piedrahita, and Osvaldo Vigil-Galán. "SnS-based thin film solar cells: perspectives over the last 25 years." Journal of Materials Science: Materials in Electronics, Vol. 26, Issue. 7, pp 4541-4556, 2015.

[7] Sall, Thierno, Miguel Mollar, and Bernabé Marí. "Substrate influences on the properties of SnS thin films deposited by chemical spray pyrolysis technique for photovoltaic applications." Journal of materials science, Vol. 51, Issue. 16, pp 7607-7613, 2016.

[8] Calixto-Rodriguez, M., H. Martinez, A. Sanchez-Juarez, J. Campos-Alvarez, A. Tiburcio-Silver, and M. E. Calixto. "Structural, optical, and electrical properties of tin sulfide thin films grown by spray pyrolysis." Thin solid films, Vol. 517, Issue. 7, pp 2497-2499, 2009.

[9] Vijayakumar, K., C. Sanjeeviraja, M. Jayachandran, and L. Amalraj. "Characterization of Tin disulphide thin films prepared at different substrate temperature using spray pyrolysis technique." Journal of Materials Science: Materials in Electronics, Vol. 22, Issue. 8, pp 929-935, 2011.

[10] Anca, Duta, Dana Perniu, Luminita Isac, and Alexandru Enesca. "Solar Energy Materials Obtained by Spray Pyrolysis Deposition."

[11] Mani, P., K. Manikandan, and J. Joseph Prince. "Influence of molar concentration on triethanolamine (TEA) added tin sulfide (SnS) thin films by SILAR method." Journal of Materials Science: Materials in Electronics, Vol. 27, Issue. 9, pp 9255-9264, 2016.

[12] Patel, Malkeshkumar, and Abhijit Ray. "Magnetron sputtered $\mathrm{Cu}$ doped SnS thin films for improved photoelectrochemical and heterojunction solar cells." Rsc Advances, Vol. 4, Issue. 74, pp 39343-39350, 2014.

[13] E. Guneri, C. Ulutas, F. Kirmizigul, G. Altindemir, F. Gode, C. Gumus "Effect of deposition time on structural, electrical, and optical properties of SnS thin films deposited by chemical bath deposition” Applied Surface Science, Vol. 257, pp 1189-1195, 2010. 
[14] D. Avellaneda, B. Krishnan, T.K. Das Roy, G.A. Castillo, S. Shaji "Modification of structure, morphology and physical properties of tin sulfide thin films by pulsed laser irradiation" Appl Phys A, Vol. 110, pp 667-672, 2013.

[15] Mundher Al-Shakban, Zhiqiang Xie, Nicky Savjani, M. Azad Malik, and Paul O'Brien "A facile method for the production of SnS thin films from melt reactions" J Mater Sci, Vol. 51, pp 61666172, 2016.

[16] K. Santhosh Kumar, C. Manoharan, S. Dhanapandian, A. Gowri Manohari "Effect of Sb dopant on the structural, optical and electrical properties of SnS thin films by spray pyrolysis technique" Spectrochimica Acta Part A: Molecular and Biomolecular Spectroscopy, Vol. 115, pp 840-844, 2013.

[17] R. Mariappan, V.Ponnuswamy, P.Suresh, R.Suresh, M.Ragavendar, C. Sankar "Deposition and characterization of pure and $\mathrm{Cd}$ doped $\mathrm{SnO} 2$ thin films by the nebulizer spray Pyrolysis (NSP)technique" Materials Science in Semiconductor Processing Vol. 16, pp 825-832, 2013.

[18] F. de Moure-Flores, J.G. Quĩnones-Galvan, A. HernandezHernandez, A. Guillen-Cervantes, M.A. Santana-Aranda, M. de la L. Olvera, M. Melendez-Lira "Structural, optical and electrical properties of $\mathrm{Cd}$-doped $\mathrm{SnO} 2$ thin films grown by $\mathrm{RF}$ reactive magnetron co-sputtering" Applied Surface Science, Vol. 8, pp 2459-2463, 2012.

[19] A Salem, S S Ahmed, \& S N Alamri "Structural and optical properties of nanocrystalline tin sulfide thin films deposited by thermal evaporation" Indian journal of pure and applied physics, Vol. 53, 2015.

[20] M. Girish, R. Sivakumar and C. Sanjeeviraja "A Simple Approach to Deposit MnS Thin Films" AIP Conf. Proc. Vol. 1620, pp 235239, 2014.

[21] Sall, Thierno, Miguel Mollar, and Bernabé Marí. "Substrate influences on the properties of SnS thin films deposited by chemical spray pyrolysis technique for photovoltaic applications." Journal of materials science, Vol. 51, Issue. 16, pp 7607-7613, 2016.

[22] Henry, J., K. Mohanraj, S. Kannan, S. Barathan, and G. Sivakumar. "Structural and optical properties of SnS nanoparticles and electron-beam-evaporated SnS thin films." Journal of Experimental Nanoscience, Vol. 10, Issue. 2, pp 78-85, 2015.

[23] Yadav, A. A., M. A. Barote, and E. U. Masumdar. "Studies on nanocrystalline cadmium sulphide $(\mathrm{CdS})$ thin films deposited by spray pyrolysis." Solid state sciences, Vol. 12, Issue. 7, pp 11731177, 2010.

[24] Leach, Mark, KT Ramakrishna Reddy, M. V. Reddy, J. K. Tan, D. Y. Jang, and R. W. Miles. "Tin sulphide thin films synthesised using a two step process." Energy Procedia, Vol. 15, pp 371-378, 2012.

[25] CH. Ashok, K. Venkateswara Rao, CH. Shilpa Chakra, K. Ganapathi Rao "Structural and Optical Properties of CdS Thin films for the Solar Cell Applications" International Journal of Science and Research (IJSR) ISSN (Online): 2319-7064.

[26] Y1lmaz, Salih. "The investigation of spray pyrolysis grown CdS thin films doped with flourine atoms." Applied Surface Science, Vol. 357, pp 873-879, 2015.

[27] L. C. Nehru, M. Umadevi, C. Sanjeeviraja "Studies on Structural, Optical and Electrical Properties of $\mathrm{ZnO}$ Thin Films Prepared by the Spray Pyrolysis Method" International Journal of Materials Engineering, Vol. 2, Issue. 1, pp 12-17, 2012.

\section{AUTHORS PROFILE}

Dr. M.Karunakaran is currently working as an Assistant Professor in Department of Physics, Alagappa Government Arts College, Karaikudi. He has published more than 50 research papers in reputed international journals and it's also available online. His main research work focuses on Materials Science (Thin films and Nano materials synthesis) He has 13 years of teaching experience and 10 years of research experience.

Mr. K.Kasirajan perused M. Phil., (Physics) in 2015 from Alagappa Government Arts College, Karaikudi, (TN), India. Currently, he is doing Ph.D. from Alagappa University, Karaikudi, (TN), India. His area of research is Synthesis and Characterization of Dilute magnetic Semiconducting thin films, Nanoparticles and Green Synthesis etc. He has published more than 20 papers in International Journals. 